\title{
重要胡麻栽培品种的抗旱性综合评价及指标篮选
}

\author{
罗俊杰 ${ }^{1}$ 欧巧明 ${ }^{1, *}$ 叶春雷 ${ }^{1}$ 王 方 $^{1}$ 王镛臻 $^{2}$ 陈玉梁 ${ }^{1, *}$ \\ ${ }^{1}$ 甘肃省农业科学院生物技术研究所, 甘肃兰州 $730070 ;{ }^{2}$ 甘肃农业大学资源与环境学院, 甘肃兰州 730070
}

摘 要: 以 15 份国内胡麻栽培品种为材料, 设自然降雨和正常灌水 2 个处理, 考察与抗旱性相关的 7 个农艺性状、8 个生理生化指标及产量指标, 采用综合抗旱系数、因子分析、隶属函数、聚类分析和灰色关联度分析相结合的方法, 对 其抗旱性进行综合评价、抗旱型划分和评价指标篮选。结果显示，相关性状指标对干旱胁迫的反应及关联程度各异， 可优先选择与抗旱性关系密切的产量及其相关性状、光合作用因子、叶片抗氧化因子等相关生理生化性状; 因子分 析表明, 6 个公因子可代表胡麻抗旱性 90.89\%的原始数据信息量。基于抗旱性度量值(drought resistance comprehensive evaluation values, D 值)和加权抗旱系数(weight drought resistance coefficient, WDC 值)的各品种抗旱性排序相近, 位居 前 6 位的抗旱品种相同。各品种 D 值与综合抗旱系数(comprehensive drought resistance coefficient, CDC 值)、WDC 值、 产量抗旱系数 (yield drought resistance coefficient, Y 值)之间均呈极显著正相关, 而各品种 Y 值与 CDC、WDC 值间极 显著正相关; 据 D 值将供试品种划分为 5 个抗旱级别, 可较好地反映品种的选育条件及适应地区。试验结果说明以 $\mathrm{D}$ 值为主要参数, 以 WDC 为辅助评价参数, 评价以产量为主要考量目标的胡麻抗旱性是适宜且准确的; 以抗旱性综 合评价方法进行胡麻抗旱性综合评价、抗旱型划分、评价指标篮选是准确的。

关键词：胡麻；农艺性状；生理生化指标；抗旱性综合评价；隶属函数

\section{Comprehensive Valuation of Drought Resistance and Screening of Indices of Important Flax Cultivars}

\author{
LUO Jun-Jie ${ }^{1}$, OU Qiao-Ming ${ }^{1, *}$, YE Chun-Lei ${ }^{1}$, WANG Fang ${ }^{1}$, WANG Yong-Zhen ${ }^{2}$, and CHEN Yu-Liang ${ }^{1, *}$ \\ ${ }^{1}$ Biotechnology Institute, Gansu Academy of Agricultural Sciences, Lanzhou 730070, China; ${ }^{2}$ College of Resources and Environmental Sciences, \\ Gansu Agricultural University, Lanzhou 730070, China
}

\begin{abstract}
Seven main agronomic traits, eight physiological indices and yield index of 15 main flax cultivars in China were measured during maturity under the conditions of irrigation and natural rainfall. Comprehensive drought resistance coefficient (CDC value), factor analysis, subordinate function coefficients, clustering analysis, grey relational analysis were used to evaluate the drought resistance, classify drought resistance type and select evaluation indices in tested flax cultivars. The response to drought stress and correlations of tested traits and indices were different. Yield and photosynthesis factors as well as leaf antioxidant factors were closely associated with drought resistance, so could be used as priority indicator of drought resistance evaluation. Factor analysis showed that six common factors could represent $90.89 \%$ of the original information of flax drought resistance data. The ranks of drought resistance of tested flax cultivars based on drought resistance comprehensive evaluation values (D value) and weight drought resistance coefficient (WDC value) were similar, the drought resistance was the same for six flax cultivars, arranging from the first to third in drought resistance. D values of tested flax cultivars had significant and positive correlation with CDC value, WDC value and Y value. Y values of tested flax cultivars also had very significant and positive correlation with CDC value and WDC value. According to D value clustering analysis, tested cultivars were divided into five grades in drought resistance, reflecting the diffirence of cultivars in breeding condition and adaptive region growing well. Drought resistance evaluated mainly with yield by D value as index and WDC value as auxiliary index in flax were appropriate and accurate. Drought resistance comprehensive evaluation methods can be used in studying exactly drought resistance evaluation, classification of drought
\end{abstract}

\footnotetext{
本研究由国家现代农业产业技术体系建设专项(CARS-17-SYZ-6)资助。

* 通讯作者(Corresponding authors)：欧巧明, E-mail: ouqiaoming@163.com, Tel: 0931-7612685; 陈玉梁, E-mail: cheny1925@163.com, Tel: 0931-7616636

第一作者联系方式: E-mail: hnsljjie@163.com, Tel: 0931-7612658

Received(收稿日期): 2013-11-18; Accepted(接受日期): 2014-03-04; Published online(网络出版日期): 2014-04-09.

URL: http://www.cnki.net/kcms/detail/11.1809.S.20140409.1118.008.html
} 
resistant type and screening evaluation indices in flax.

Keywords: Flax; Agronomic traits; Physiological and biochemical indices; Drought resistance comprehensive evaluation; Subordinate function coefficients

胡麻(Linum usitatissimum L.)即油用亚麻, 是中 国西北、华北等年降水量300 500 mm的旱作农业区 重要的油料作物 ${ }^{[1-3]}$, 具有耐痊薄、喜阴凉、耐旱、 耐寒等特点, 在抗旱资源方面具有独特研究价值。 研究国内胡麻品种抗旱性及其综合评价方法和鉴定 指标, 对胡麻抗旱育种、抗旱资源利用及品种的生 产应用与合理布局具有重要意义。

作物抗旱性鉴定需要将形态、生理生化、产量 等指标相结合, 且对各个时期的抗旱性综合评价 ${ }^{[4]}$ 。 因此，简单、有效的鉴定指标及其评价方法的合理 选择是抗旱性鉴定的关键 ${ }^{[2]}$ 。近年来, 国内外学者从 不同角度研究和提出了作物抗旱性鉴定的试验设 计、指标选择、评价方法及抗旱性分级等问题 ${ }^{[1,2,5-10]}$, 针对不同作物和不同育种需求的更加全面的抗旱评 价方法已在小麦 ${ }^{[1,11]}$ 、大豆 ${ }^{[12-13]}$ 、油菜 ${ }^{[14-15]}$ 、谷子 ${ }^{[16]}$ 、 水稻 ${ }^{[9]} 、 玉$ 米 ${ }^{[17]}$ 、棉花 ${ }^{[18]}$ 、胡麻 ${ }^{[2,19]}$ 等作物上应用, 如 主成分分析法、隶属函数法、聚类分析法等。目前 普遍认为, 多指标多方法相结合的抗旱性综合评价 更加真实、可靠 ${ }^{[2]}$ 。

前人研究多侧重于以胡麻种质资源为材料 ${ }^{[2]}$ 或 针对某种农艺性状、生理生化指标单独分析，而针 对胡麻抗旱相关生理指标且采用抗旱性综合评价方 法的研究鲜见报道。为了探讨国内胡麻栽培品种抗 旱性及其与主要性状间的关系。本研究在分析干旱 处理和灌水条件下与胡麻抗旱性相关的多个农艺性 状及生理生化性状基础上, 对国内 15 个胡麻栽培品 种的抗旱性综合评价, 试图明确其抗旱性评价中可 借鉴的性状指标及简单、可靠的方法, 以期为抗旱 育种及品种生产应用提供参考。

\section{1 材料与方法}

\section{1 试验材料与处理}

分别于 2011 年和 2012 年在甘肃省兰州市榆中 县良种场种植 15 份目前国内主要胡麻种植区大面 积应用的育成品种(表 1)。试验点海拔 $1480 \mathrm{~m}$ 、年平 均气温 $6.7^{\circ} \mathrm{C}$ 、无霜期 $148 \mathrm{~d}$ 、年平均降水量 $381.6 \mathrm{~mm}$ 、年蒸发量 $1343.1 \mathrm{~mm}$ 。所选试验地含有 机质 $17.13 \mathrm{~g} \mathrm{~kg}^{-1}$ 、全氮 $0.94 \mathrm{~g} \mathrm{~kg}^{-1}$ 、全磷 $0.76 \mathrm{~g} \mathrm{~kg}^{-1}$ 、 全钾 $22.98 \mathrm{~g} \mathrm{~kg}^{-1}$ 、碱解氮 $38.65 \mathrm{mg} \mathrm{kg}^{-1}$ 、速效磷 $24.37 \mathrm{mg} \mathrm{kg}^{-1}$ 、速效钾 $132.67 \mathrm{mg} \mathrm{kg}^{-1}, \mathrm{pH} 7.88$ 。
采用随机区组排列, 分别设干旱胁迫 (自然降雨, 全生育期不灌溉)和对照(全生育期灌水 2 次) 2 个处 理, 重复 3 次。每处理 15 个品种, 小区面积 $24 \mathrm{~m}^{2}$ $(6 \mathrm{~m} \times 4 \mathrm{~m})$, 行距 $20 \mathrm{~cm}$, 于 4 月 7 日人工开沟撒播, 种植密度 900 万粒 $\mathrm{hm}^{-2}$, 干旱胁迫与对照处理间隔 $5 \mathrm{~m}$, 种植保护区, 处理间小区边界均用培土分离, 播种前施尿素 $300 \mathrm{~kg} \mathrm{hm}^{-2}$ 和磷酸二氢铵 $150 \mathrm{~kg} \mathrm{hm}^{-2}$, 按当地大田生产管理。

\section{2 试验区胡麻生育期降水及土壤水分状况}

图 1 反映了 2011-2012 年试验区胡麻全生育期 (1 月至 8 月)降雨量的动态趋势, 反映出本试验区降 雨时空分布不均衡的特征, 说明自然降雨是胡麻生 长季节干旱胁迫时水分的唯一补给来源。图 2 反映 了 2011-2012 年试验区田间土壤含水量(soil water content, SWC)测试结果及其动态趋势, 相同处理不 同土层深度 SWC 间差异明显(图 2); 同一土层深度 在盛花前期 (6 月 9 日) (均值差 $d j=-1.344, t=0.474$, $P=0.478$ )和盛花后期 (7 月 16 日) (均值差 $d j=-0.278$, $t=0.4203, P=0.6853)$ 在干旱胁迫和正常灌水处理 间 SWC 差异不显著，但在盛花期(6月 27 日) (均值 差 $d j=-6.578, t=17.364, P=0.0001)$ 差异达极显著 水平(图 2), 相同处理 3 个测定时间的 SWC 差异亦 达显著或极显著水平。说明干旱胁迫处理在胡麻盛 花期 SWC 下降最明显, 水分透支严重, 胡麻受干旱 胁迫亦最显著，说明在该区域正常年份利用自然降 雨控制田间水分，实现对胡麻的干旱胁迫并加以研 究是可行的。所以选择以盛花期篮选抗旱指标及评 价抗旱性。

\section{3 考察性状与方法}

在胡麻盛花期对每小区每品种材料取样，参考 邹琦 ${ }^{\left[{ }^{[20]}\right.}$ 的《植物生理学实验指导》的方法, 分别测 定相关生理生化性状(表3)。采用 $80 \%$ 丙酮-无水乙醇 浸提比色法 $\left(\mathrm{mg} \mathrm{g}^{-1}\right)$ 测定叶片叶绿素 a (chlorophyll a, $\mathrm{Chl}$ a)、叶绿素 b (chlorophyll b, Chl b)和总叶绿素 (total chlorophyll, TChl)含量, 采用硫代巴比妥酸比 色法 $\left(\mu \mathrm{mol} \mathrm{mg}^{-1}\right.$ ) 测定丙二醛含量 (malondialdehyde, MDA); 采用紫外吸收法 $\left(\mathrm{U} \mathrm{mg}^{-1} \mathrm{~min}^{-1}\right)$ 、抑制 NBT 光还原比色法 $\left(\mathrm{U} \mathrm{mg}^{-1}\right)$ 、愈创木酚法 $\left(\mathrm{U} \mathrm{mg}^{-1} \mathrm{~min}^{-1}\right)$ 分别测定过氧化氢酶(catalase, CAT)活性、超氧化物 歧化酶(superoxide dismutase, SOD)活性、过氧化物 


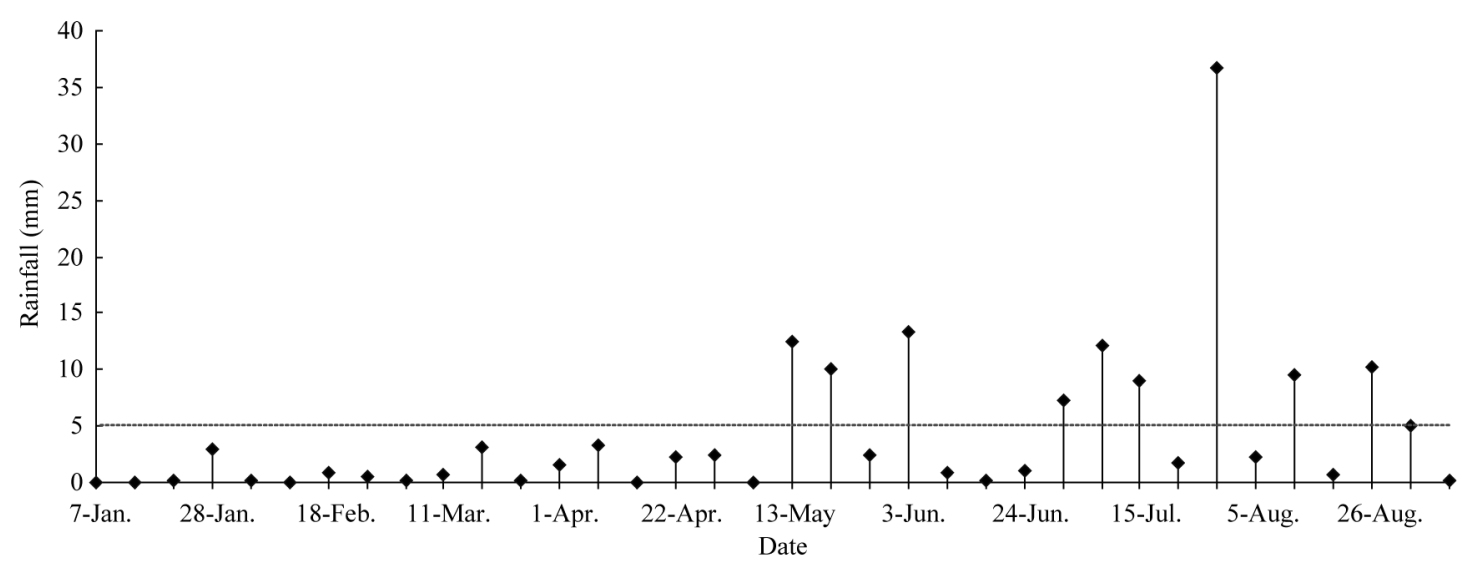

图 $12011-2012$ 年试验区胡麻全生育期(1 月至 8 月)旬降雨量动态

Fig. 1 Dynamic of average rainfall of each ten-day at the whole growth period (from Jan. to Aug.) of flax in 2011-2012

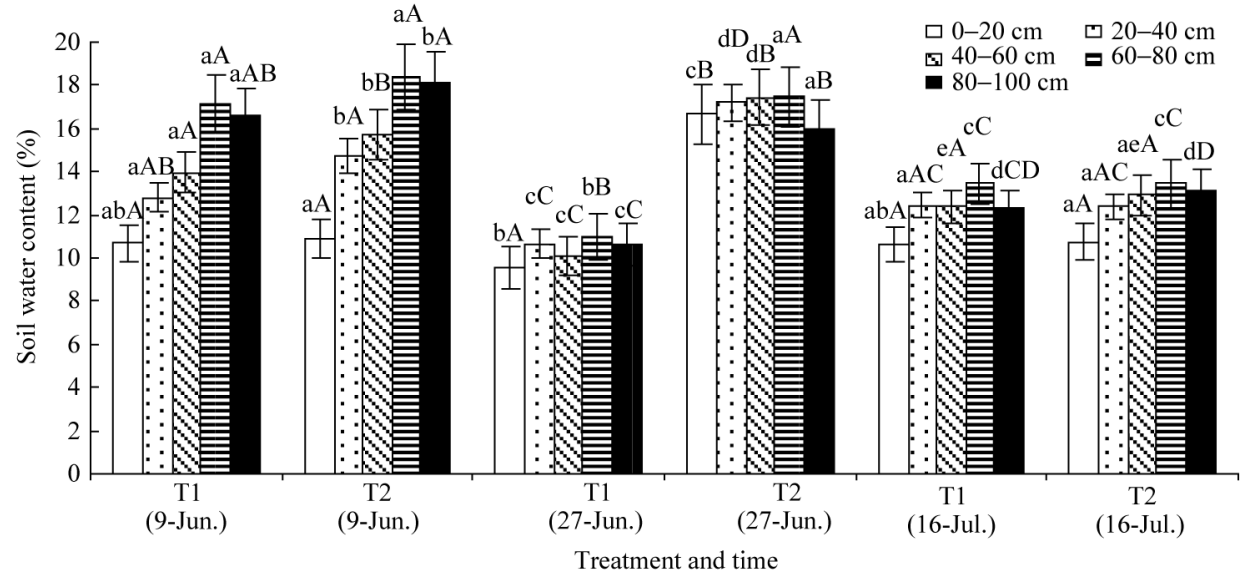

图 2 胡麻生育期不同土层深的土壤水分变化

Fig. 2 Soil moisture changes of different depth in different seasons of flax growth period

$\mathrm{T} 1$ : 干旱胁迫处理; $\mathrm{T} 2$ : 正常灌溉处理。不同字母(不同处理及测定时段同一土层深度间)表示在 0.05 水平显著(小写字母)或在 0.01 水 平极显著(大写字母)。

T1: drought-stress treatments; T2: irrigated treatments. Lowercases (capitals) alove the lans show significant difference at $0.05(0.01)$ probability levels (among same soil depth under different treatments and measured periods).

酶(peroxidase，POD)活性，采用电导仪法测定细胞 膜透性。每小区每品种材料取样 3 份, 每份样品重复 测定 3 次, 并计算平均值, 最后取两年度平均值作为 供试指标测定值。

在胡麻成熟后每小区每品种取样 20 株考种，参 照《胡麻种质资源描述规范和数据标准》 ${ }^{[21]}$, 测定 株高、工艺长度、有效分枝数、单株果数、不实果 数、单株产量、千粒重等产量相关农艺性状, 全区 收获统计小区产量, 求其平均值, 最后取两年度平 均值作为供试性状测定值。

\section{4 数据统计分析}

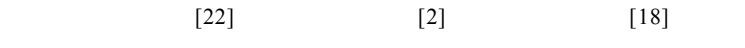
小玉等 ${ }^{[15]}$ 、孟庆立等 ${ }^{[16]}$ 和尹利等 ${ }^{[23]}$ 的方法, 以 2011 和 2012年供试胡麻品种各小区农艺性状和生理生化 性状测定值作为基础数据, 对各性状测定值进行平
均数差异显著性分析, 按公式(1)和(2)分别计算单项 抗旱系数(drought resistance coefficient, DC)及综合 抗旱系数 (comprehensive drought resistance coefficient, $\mathrm{CDC})$, 式中 $x_{i}, C K_{i}$ 表示干旱、对照处理的性 状测定值。

$$
\begin{aligned}
& D C=\frac{x_{i}}{C K_{i}}, \quad i=1,2,3, \ldots, n \\
& C D C=\frac{1}{n} \sum_{i=1}^{n} D C, \quad i=1,2,3, \ldots, n
\end{aligned}
$$

按公式(3)计算因子权重系数 $\left(\omega_{i}\right)$, 式中 $P_{i}$ 为第 $i$ 个综合指标贡献率，表示第 $i$ 个指标在所有指标中 的重要程度。

$$
\omega_{i}=P_{i} \div \sum_{i=1}^{n} P_{i}, \quad i=1,2,3, \ldots, n
$$

按公式(4)计算各基因型各综合指标的隶属函数 
值 $\left[\mu\left(x_{i}\right)\right]$, 式中 $x_{i} 、 x_{i \min } 、 x_{i \max }$ 分别表示第 $i$ 个综合指 标及第 $i$ 个综合指标的最小值、最大值。

$$
\mu\left(x_{i}\right)=\frac{x_{i}-x_{i \min }}{x_{i \max }-x_{i \min }}, \quad i=1,2,3, \ldots, n
$$

根据因子权重 $\left(\omega_{i}\right)$ 及隶属函数值 $\left[\mu\left(x_{i}\right)\right]$, 按公式 (5)计算抗旱性度量值 (drought resistance comprehensive evaluation values, D)。

$$
D=\sum_{i=1}^{n}\left[\mu\left(x_{i}\right) \times\left(P_{i} \div \sum_{i=1}^{n} P_{i}\right)\right], \quad i=1,2,3, \ldots, n
$$

按公式(6)、(7)计算关联系数 $\left(\xi_{i}\right)$ 及关联度 $\left(\gamma_{i}\right)$, 式中 $\min _{i} \min _{k}\left|x_{0}(k)-x_{i}(k)\right|$ 为二级最小差, $\max _{i} \max _{k}\left|x_{0}(k)-x_{i}(k)\right|$ 为二级最大差, $\rho$ 为分辨系数 (取值0.5)。

$$
\xi_{i}(k)=
$$

$$
\frac{\min _{i} \min _{k}\left|x_{0}(k)-x_{i}(k)\right|+\rho \max _{i} \max _{k}\left|x_{0}(k)-x_{i}(k)\right|}{\left|x_{0}(k)-x_{i}(k)\right|+\rho \max _{i} \max _{k}\left|x_{0}(k)-x_{i}(k)\right|}
$$$$
k=1,2,3, \ldots, n ; i=1,2,3, \ldots, n
$$

$$
\gamma_{i}=\frac{1}{n} \sum_{k=1}^{n} \xi(k), \quad k=1,2,3, \ldots, n
$$

根据各性状关联度 $\gamma_{i}$, 按公式(8)计算各性状指 标权重系数 $\left[\omega_{i(\gamma)}\right]$, 并据公式(9)计算加权抗旱系数 (weight drought resistance coefficient, WDC), 式中 $\gamma_{i}$ 为各基因型关联度。

$$
\begin{aligned}
& \omega_{i(\gamma)}=\frac{1}{n} \sum_{i=1}^{n} \gamma_{i}, \quad i=1,2,3, \ldots, n \\
& W D C=\sum_{i=1}^{n}\left[D C \times \frac{1}{n} \sum_{i=1}^{n} \gamma_{i}\right], \quad i=1,2,3, \ldots, n
\end{aligned}
$$

最后针对供试胡麻品种 $\mathrm{D}$ 值, 采用欧式距离和 加权配对算术平均法(weighted pair group method average, WPGMA)进行聚类分析, 划分抗旱级别; 并分别以 $\mathrm{D}$ 值、 $\mathrm{CDC}$ 值、 $\mathrm{WDC}$ 值为参考序列, 对各 性状DC值进行逐步回归分析, 求取回归方程。

采用Microsoft Excel 2003和SPSS 18.0分析软件 处理数据。

\section{2 结果与分析}

\section{1 试验材料的代表性及其性状测定值分析}

供试胡麻品种主要农艺性状两年度测定平均值 的差异显著性分析(配对处理 $t$ 检验)表明(表1), 干旱 对供试品种主要农艺性状测定值均有显著影响, 除 有效分枝数外 $(P>0.05)$, 处理间差异均达极显著水 平 $(P<0.01)$, 品种间差异亦达显著水平 $(P<0.05)$, 品
种间变异系数介于 $0.061 \sim 0.543$ 。说明本试验所选胡 麻品种类型较丰富, 所选主要农艺性状对干旱胁迫 反应较为敏感, 干旱处理试验效果较好, 具有较好 代表性。

供试品种主要生理指标 2 年度测定平均值的差 异显著性分析表明(表2), 干旱对供试品种生理指标 测定值均有明显影响, 除TChl、CAT外 $(P>0.05)$, 处 理间差异均达显著 $(P<0.05)$ 或极显著水平外 $(P<0.01)$, 品种间差异亦达显著水平 $(P<0.05)$, 品种间变异系 数介于 0.037 1.382。说明本试验干旱处理效果较好, 但所选主要生理指标对干旱胁迫反应敏感性不同, 除TChl、CAT外, 其余指标均较为敏感, 具有较好代 表性。

另外, 表 1 和表 2 还显示供试品种各性状在干旱 和正常处理下的测定值相关性差异较大, 这进一步 说明各性状敏感性存在较大差异, 采用各性状测定 值难以直接考量其抗旱性。

\section{2 单项指标与胡麻品种的抗旱性分析}

根据 1.4 节中公式(1)获得各性状抗旱系数(DC 值)(表 3), 分析表明, 与正常灌水处理相比, 供试品 种在生育期持续干旱处理后, 所选性状均发生了不 同程度变化。同一性状各品种的 DC 值差异明显, 变 异系数介于 $0.020 \sim 0.385$ 之间, 但不同品种间 DC 值 所反映的抗旱性不同, 且同一品种各性状的 DC 值 存在较大差异(表 3), 说明各性状指标对干旱胁迫的 敏感程度各异, 且所测指标间的关系复杂, 有必要 借助综合抗旱系数(CDC 值)及因子分析确定其权重 系数 $(\omega)$ 后进行抗旱性综合评价。

采用综合抗旱系数公式(2)获得供试品种 CDC 值, $\mathrm{CDC}$ 值介于 $0.770 \sim 1.024$ 之间, 变异系数为 0.079。根据 CDC 值大小对供试品种进行抗旱性排 序(表 3 和表 6), 15 个供试品种的抗旱性强弱顺序为 天亚 9 号、晋亚 7 号、坝亚 12、伊亚 4 号、轮选 2 号、宁亚 19、陇亚杂 2 号、陇亚 10 号、陇亚 8 号、 陇亚 11、定亚 23、晋亚 10 号、晋亚 11、坝选 3 号。

通过各性状 DC 值的连续变数次数分布统计分 析 ${ }^{[2]}$, 表明同一区间各性状 DC 值分布次数和频率相 差较大, $\mathrm{DC}$ 值在 $0.9<\mathrm{DC}<1.2$ 区间的千粒重、有效分 枝数的分布频率分别为 $73.33 \%$ 和 $53.33 \%$, DC 值在 $0.6<\mathrm{DC}<0.9$ 区间的单株果实、MP、SOD、POD、产 量等指标的分布频率也均大于 $60.0 \%$, 而株高、工艺 长度、MDA、Chl b 的 DC 值在此区间分布频率达 $100.0 \%$ (表 4)。说明千粒重、有效分枝数对干旱胁 


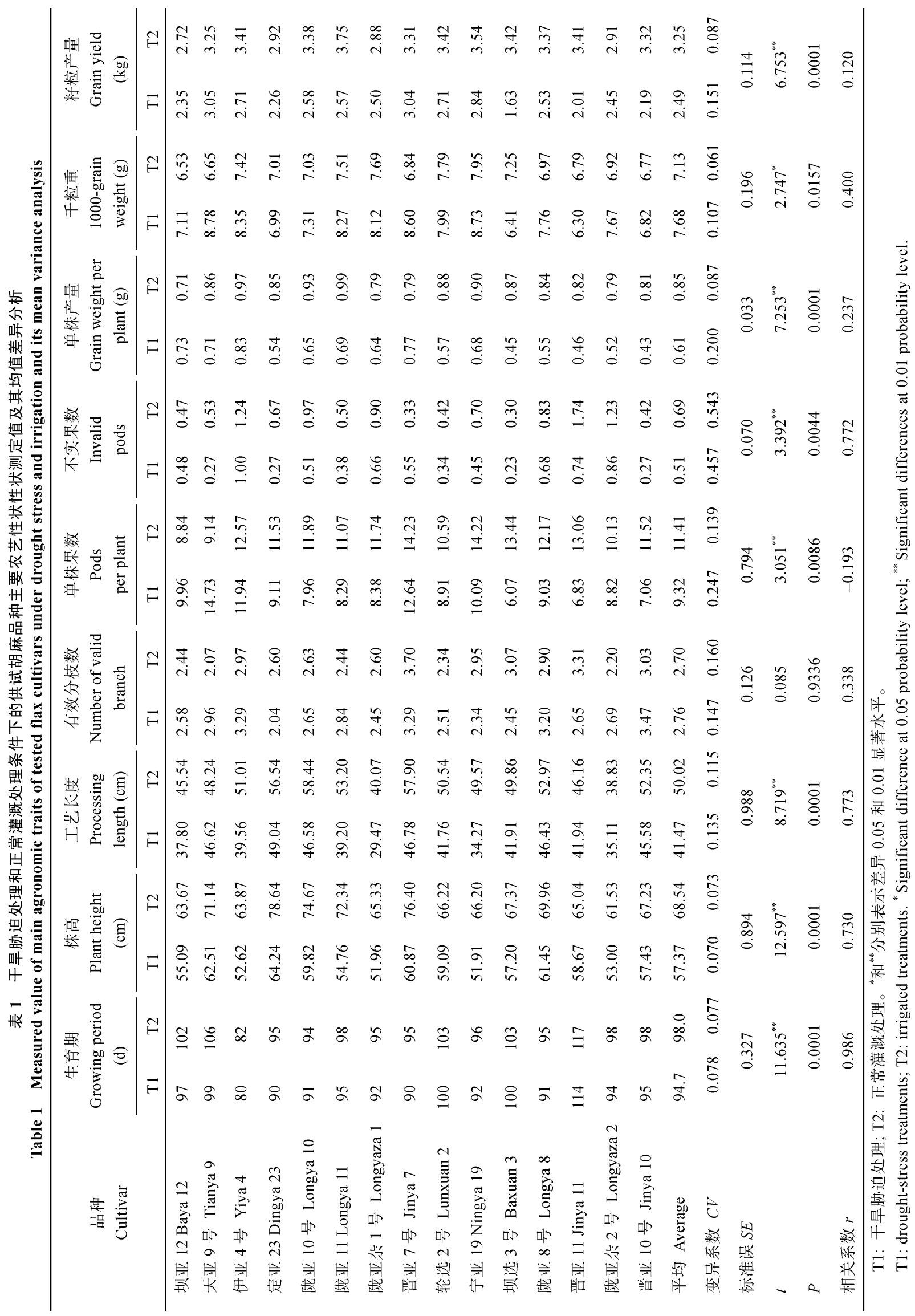




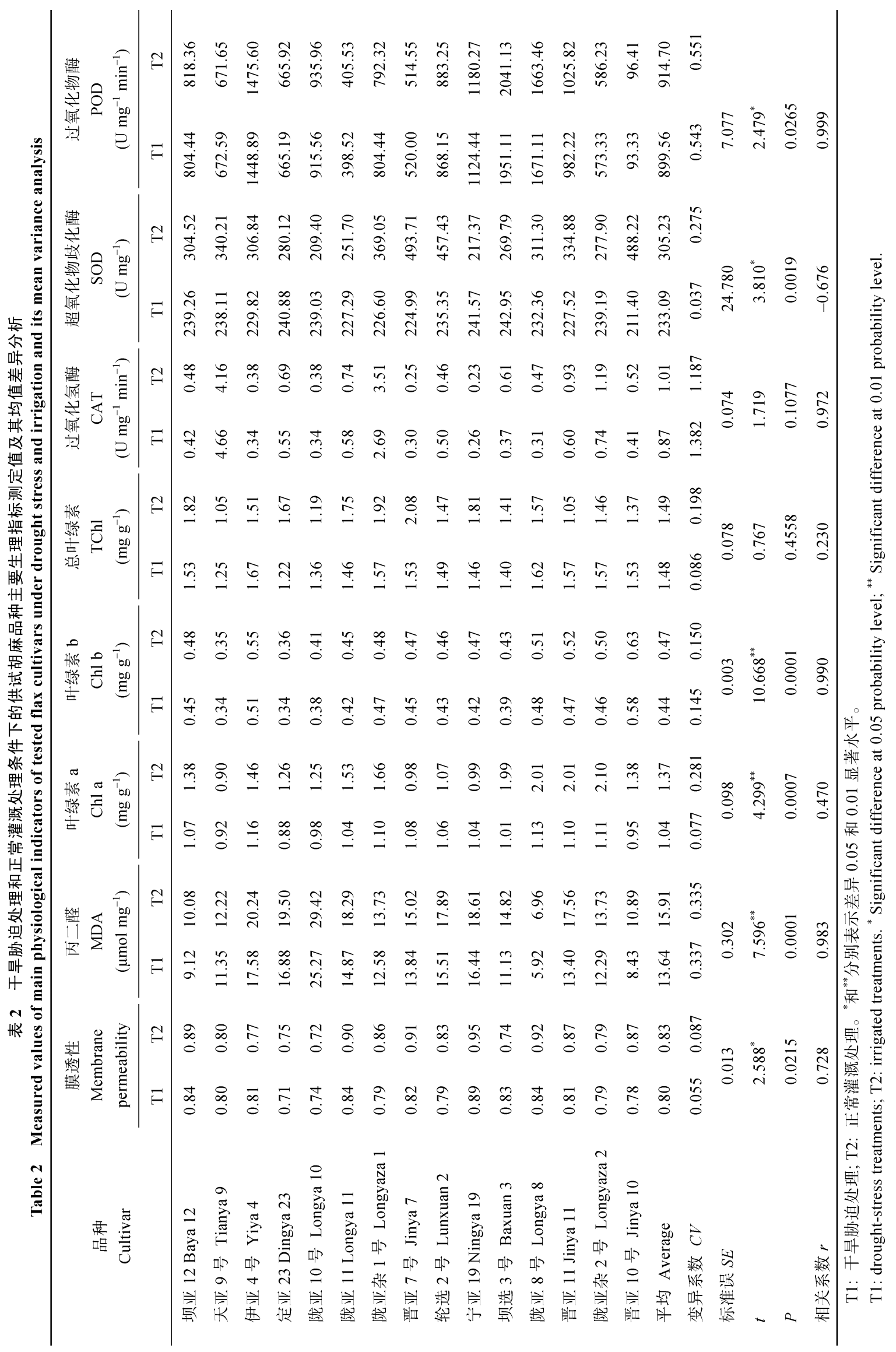




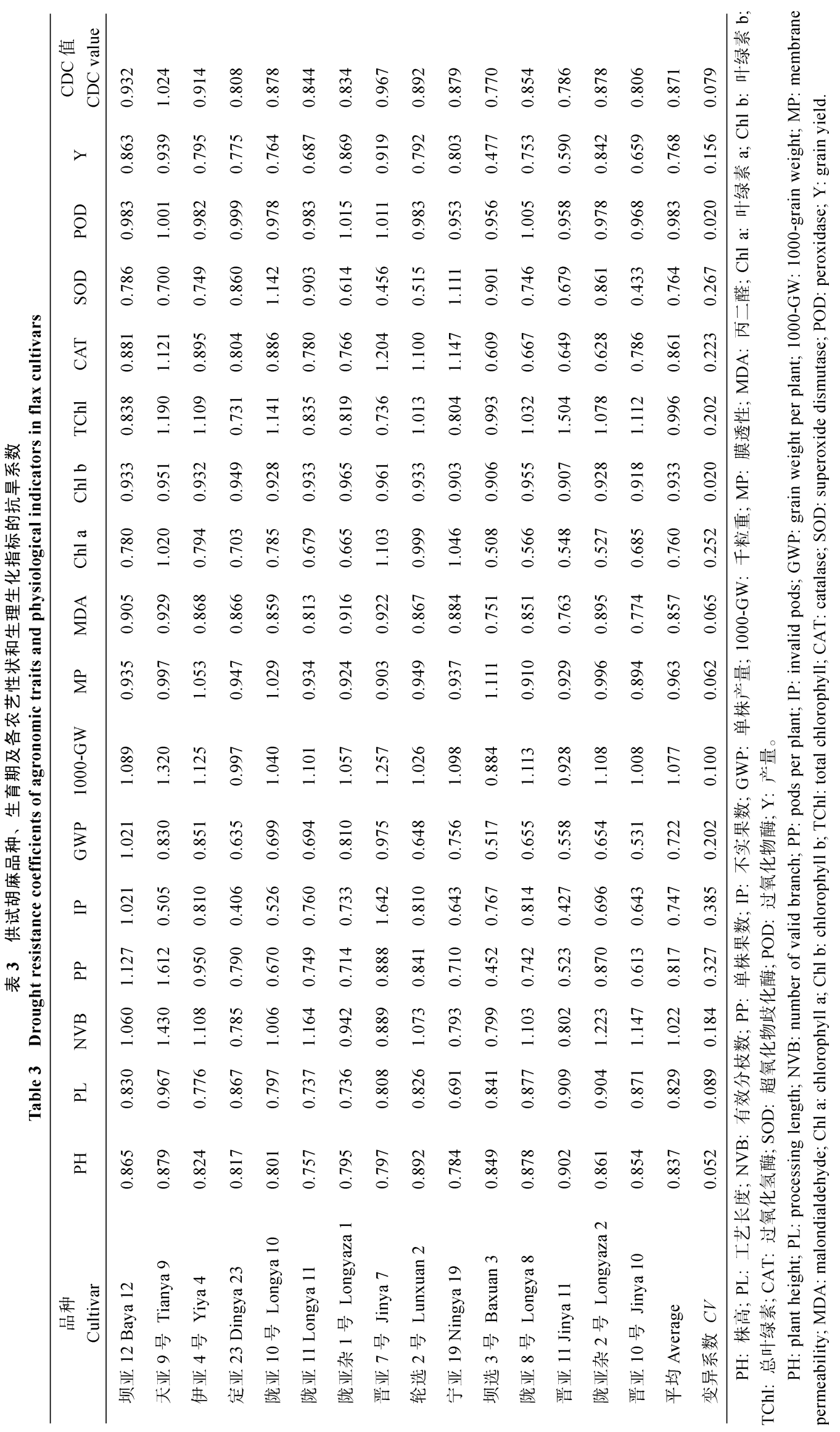


表 4 供试胡麻品种各性状指标的抗旱系数及其在不同区间的分布

Table 4 Drought resistance coefficient of traits indices and diffirent distributions of tested flax cultivars

\begin{tabular}{|c|c|c|c|c|c|c|c|c|c|c|}
\hline \multirow{2}{*}{$\begin{array}{l}\text { 性状 } \\
\text { Trait }\end{array}$} & \multicolumn{2}{|c|}{$0.3<\mathrm{DC}<0.6$} & \multicolumn{2}{|c|}{$0.6<\mathrm{DC}<0.9$} & \multicolumn{2}{|c|}{$0.9<\mathrm{DC}<1.2$} & \multicolumn{2}{|c|}{$1.2<\mathrm{DC}<1.5$} & \multicolumn{2}{|c|}{$1.5<\mathrm{DC}<1.8$} \\
\hline & $\begin{array}{l}\text { 次数 } \\
\text { Times }\end{array}$ & $\begin{array}{c}\text { 频次 } \\
\text { Freq. (\%) }\end{array}$ & $\begin{array}{l}\text { 次数 } \\
\text { Times }\end{array}$ & $\begin{array}{c}\text { 频次 } \\
\text { Freq. (\%) }\end{array}$ & $\begin{array}{l}\text { 次数 } \\
\text { Times }\end{array}$ & $\begin{array}{c}\text { 频次 } \\
\text { Freq.(\%) }\end{array}$ & $\begin{array}{l}\text { 次数 } \\
\text { Times }\end{array}$ & $\begin{array}{c}\text { 频次 } \\
\text { Freq. (\%) }\end{array}$ & $\begin{array}{l}\text { 次数 } \\
\text { Times }\end{array}$ & $\begin{array}{c}\text { 频次 } \\
\text { Freq. (\%) }\end{array}$ \\
\hline 株高 Plant height & 0 & 0 & 15 & 100.00 & 0 & 0 & 0 & 0 & 0 & 0 \\
\hline 工艺长度 Processing length & 0 & 0 & 15 & 100.00 & 0 & 0 & 0 & 0 & 0 & 0 \\
\hline 有效分枝数 Number of valid branch & 0 & 0 & 6 & 40.00 & 8 & 53.33 & 1 & 6.67 & 0 & 0 \\
\hline 单株果数 Pods per plant & 4 & 26.67 & 9 & 60.00 & 1 & 6.67 & 0 & 0 & 1 & 6.67 \\
\hline 不实果数 Invalid pods & 7 & 46.67 & 6 & 40.00 & 1 & 6.67 & 0 & 0 & 1 & 6.67 \\
\hline 单株产量 Grain weight per plant & 9 & 60.00 & 5 & 33.33 & 1 & 6.67 & 0 & 0 & 0 & 0 \\
\hline 千粒重 1000-grain weight & 0 & 0 & 3 & 20.00 & 11 & 73.33 & 1 & 6.67 & 0 & 0 \\
\hline 膜透性 Membrane permeability & 0 & 0 & 12 & 80.00 & 3 & 20.00 & 0 & 0 & 0 & 0 \\
\hline 丙二醛 $\mathrm{MDA}$ & 0 & 0 & 15 & 100.00 & 0 & 0 & 0 & 0 & 0 & 0 \\
\hline 叶绿素 a Chl a & 7 & 46.67 & 5 & 33.33 & 3 & 20.00 & 0 & 0 & 0 & 0 \\
\hline 叶绿素 b Chl b & 0 & 0 & 15 & 100.00 & 0 & 0 & 0 & 0 & 0 & 0 \\
\hline 总叶绿素 TChl & 0 & 0 & 7 & 46.67 & 7 & 46.67 & 1 & 6.67 & 0 & 0 \\
\hline 过氧化氢酶 CAT & 4 & 26.67 & 7 & 46.67 & 4 & 26.67 & 0 & 0 & 0 & 0 \\
\hline 超氧化物歧化酶 SOD & 0 & 0 & 11 & 73.33 & 4 & 26.67 & 0 & 0 & 0 & 0 \\
\hline 过氧化物酶 POD & 6 & 40.00 & 7 & 46.67 & 2 & 13.33 & 0 & 0 & 0 & 0 \\
\hline 籽粒产量 Grain yield & 4 & 26.67 & 11 & 73.33 & 0 & 0 & 0 & 0 & 0 & 0 \\
\hline
\end{tabular}

Freq: frequency.

迫的反应迟钝，株高、工艺长度、MDA、Chl b 次之， 而其他性状则较为敏感。

\section{3 因子分析及因子载荷与权重系数评价}

采用因子分析对各性状指标 DC 值进一步分析, 获得特征向量、因子载荷和贡献率(表 5), 以便进一 步确定和评价抗旱鉴定的重要指标。结果表明, 各 因子特征值中前 6 个因子的累积贡献率已达到 $90.89 \%$ ，其特征根 $\lambda>0.6371$ 。抽取前 6 个因子，将具 有相同本质的变量归为一类, 可将原来各单项性状 指标转换为 6 个新的相互独立的综合指标(公因子, 用 F1、F2、F3、F4、F5、F6 表示)。公因子载荷矩 阵的载荷系数绝对值表明(表 2), F1 在单株果实、单 株产量、千粒重、 $\mathrm{Ch} 1 \mathrm{a} 、 \mathrm{CAT}$ 上有较高荷载量; F2 在株高、工艺长度、 $\mathrm{TCh}$ 上有较高载荷量; F3 在 $\mathrm{MDA} 、 \mathrm{Chl} b 、 \mathrm{SOD}$ 、产量上有较高载荷量; F4 在膜 透性、POD 上有较高载荷量; F5、F6 分别在不实果 数、有效分枝数上有较高载荷量。

在获得各公因子特征向量、贡献率的基础上, 据公式(3)计算各公因子权重系数( $\omega)$ (表 5), 用以计 算加权隶属函数值。

\section{4 隶属函数分析及其品种的综合抗旱性评价}

在获得各公因子特征向量的基础上, 利用模糊 隶属函数法, 据公式(4)计算各因子隶属函数值 $(\mu)$,
并据各因子权重系数 $(\omega)$, 对各因子隶属函数值 $(\mu)$ 赋予相应权重系数 $(\omega)$, 按公式(5)计算加权隶属函 数值, 作为综合抗旱性度量值( D 值), 据此可较准确地 评价供试品种的抗旱性, D 值越大抗旱性越强(表 6)。

供试品种 D 值介于 $0.366 \sim 0.738$ 之间，平均值 0.488 , 变异系数为 0.191 。根据 D 值大小对供试胡 麻品种进行抗旱性排序(表 6), 其顺序为天亚 9 号、 晋亚 7 号、轮选 2 号、伊亚 4 号、坝亚 12、宁亚 19、 陇亚 10 号、陇亚杂 2 号、晋亚 11 、陇亚 8 号、晋亚 10 号、定亚 23、陇亚 11 、陇亚杂 1 号、坝选 3 号。 这与基于 CDC 值的供试品种的抗旱性强弱评价结 果基本吻合。而抗旱性最强的天亚 9 号 $\mathrm{D}$ 值较所有 品种平均值高出 $11.998 \%$, 远高于其他品种, 这与各 品种在生产应用中的多年抗旱性表现相吻合。

2.5 不同性状与 $\mathrm{D}$ 值的灰色关联分析

按照公式(6)和(7), 对所有性状单项抗旱系数 (比较数列)与其 $\mathrm{D}$ 值 (参考数列) 进行灰色关联度分 析, 获得各性状 DC 值与 $\mathrm{D}$ 值间的关联度 $\left(\gamma_{\mathrm{D}}\right)$, 结果 显示各性状与 $\mathrm{D}$ 值的密切程度依次为单株果实、千 粒重、CAT、Chl a、产量、单株产量、MDA、有效 分枝、不实果数、 $\mathrm{SOD} 、 \mathrm{Chl} b$ 、膜透性、 $\mathrm{TChl}$ 、株 高、工艺长度、POD (表 7), 这和各性状 DC 值与 Y 值的关联程度相近。 
表 5 因子载荷矩阵及方差贡献率

Table 5 Rotated factor pattern and cumulative variance contribution

\begin{tabular}{|c|c|c|c|c|c|c|}
\hline \multirow{2}{*}{$\begin{array}{l}\text { 性状 } \\
\text { Trait }\end{array}$} & \multicolumn{6}{|c|}{ 因子载荷 Factor pattern } \\
\hline & F1 & $\mathrm{F} 2$ & F3 & $\mathrm{F} 4$ & F5 & F6 \\
\hline 株高 Plant height & -0.059 & 0.949 & 0.096 & -0.028 & 0.021 & 0.011 \\
\hline 工艺长度 Processing length & -0.135 & 0.891 & -0.123 & 0.015 & -0.082 & -0.193 \\
\hline 有效分枝数 Number of valid branch & 0.099 & 0.250 & -0.183 & 0.003 & -0.029 & -0.920 \\
\hline 单株果数 Pods per plant & 0.596 & 0.283 & -0.450 & 0.160 & -0.041 & -0.511 \\
\hline 不实果数 IP & 0.263 & -0.218 & -0.218 & -0.050 & 0.882 & 0.038 \\
\hline 单株产量 Grain weight per weight & 0.610 & -0.218 & -0.499 & 0.152 & 0.343 & -0.120 \\
\hline 千粒重 1000-grain weight & 0.603 & -0.047 & -0.457 & -0.027 & 0.153 & -0.562 \\
\hline 膜透性 Membrane permeability & -0.128 & 0.083 & 0.203 & 0.904 & -0.022 & -0.043 \\
\hline 丙二醛 MDA & 0.622 & -0.117 & -0.713 & 0.080 & -0.019 & -0.130 \\
\hline 叶绿素 a Chl a & 0.943 & -0.138 & -0.044 & -0.133 & 0.132 & -0.031 \\
\hline 叶绿素 b Chl b & 0.069 & -0.026 & -0.916 & -0.214 & 0.175 & -0.144 \\
\hline 总叶绿素 TChl & -0.179 & 0.673 & 0.426 & 0.057 & -0.203 & -0.244 \\
\hline 过氧化氢酶 CAT & 0.943 & -0.138 & -0.044 & -0.133 & 0.132 & -0.031 \\
\hline 超氧化物歧化酶 SOD & 0.069 & -0.026 & -0.916 & -0.214 & 0.175 & -0.144 \\
\hline 过氧化物酶 POD & -0.021 & -0.428 & 0.160 & 0.592 & -0.573 & 0.077 \\
\hline 籽粒产量 Grain yield & 0.646 & -0.058 & -0.671 & -0.079 & -0.009 & -0.242 \\
\hline 特征根 Characteristic root & 6.791 & 3.017 & 1.858 & 1.425 & 0.816 & 0.637 \\
\hline 贡献率 Contribution rate (\%) & 42.441 & 18.854 & 11.609 & 8.905 & 5.098 & 3.982 \\
\hline 累计贡献率 Cumulative contribution rate (\%) & 42.441 & 61.295 & 72.904 & 81.809 & 86.907 & 90.889 \\
\hline 因子权重 Factor weight $(\omega)$ & 0.467 & 0.207 & 0.128 & 0.098 & 0.056 & 0.044 \\
\hline
\end{tabular}

上述结果还表明, 与胡麻品种抗旱性关系最为 密切的是与产量相关的性状(如单株果实、千粒重、 单株产量、产量)，其次是与叶片抗氧化和光合作用 有关的生理生化性状(CAT、MDA、Chl a), 它们对 干旱胁迫反映最为直接, 且所受影响最大, 因而与 抗旱性关联度最大; 而株高、工艺长度与抗旱性关 联较弱。

对各性状关联度 $\left(\gamma_{\mathrm{D}}\right)$ 归一化处理后获得性状指 标权重系数 $\left[\omega_{i(\gamma)}\right]$, 进而获得供试品种加权抗旱系数 (WDC 值)(表 4), 并基于 WDC 值获得各性状关联度 $\left(\gamma_{\mathrm{WDC}}\right)($ 表 7$)$, 用以辅助评价各性状与品种抗旱性的 关联度及各品种抗旱性。各性状关联度 $\gamma_{\mathrm{WDC}}$ 与各性 状 $\gamma_{\mathrm{D}}$ 达极显著正相关 $(r=0.93)$, 说明各性状同 WDC 值的密切程度与各性状同 D 值的密切程度相近, 用 WDC 值辅助进行品种抗旱性评价是适宜且准确的。

另外，除株高、工艺长度、不实果数、膜透性、
TChl、POD 外, 其余性状 DC 值与 CDC 值、WDC 值之间均呈极显著正相关性 $(P<0.01)$, 这和所有性 状 DC 值与 D 值、Y 值均呈极显著正相关的结果相 当吻合。说明上述 6 个性状指标对干旱胁迫的敏感 程度相对较小, 但这并不足以认定它们完全不宜作 为供试品种抗旱性评价的指标。

\section{6 聚类分析及抗旱级别的划分}

图 3 表明参试 15 份胡麻品种按抗旱性在 0.60 处分为 5 类, 其中 I 级抗旱型 1 份, II 级抗旱型 4 份, III级抗旱型 3 份, IV 级抗旱型 6 份, V 级抗旱型 1 份。

按照供试胡麻品种的抗旱性聚类结果及抗旱级 别, 对供试品种及其隶属函数 $(\mu)$ 、抗旱性综合评价 指标 CDC 值、D 值及 WDC 值分级显示(表 8), 大部 分性状指标的隶属函数值 $(\mu)$ 及上述 3 个评价指标均 随抗旱级别的升高而降低, 但个别性状亦存在异常 变化。上述 3 个评价指标在不同抗旱级别上的差异 


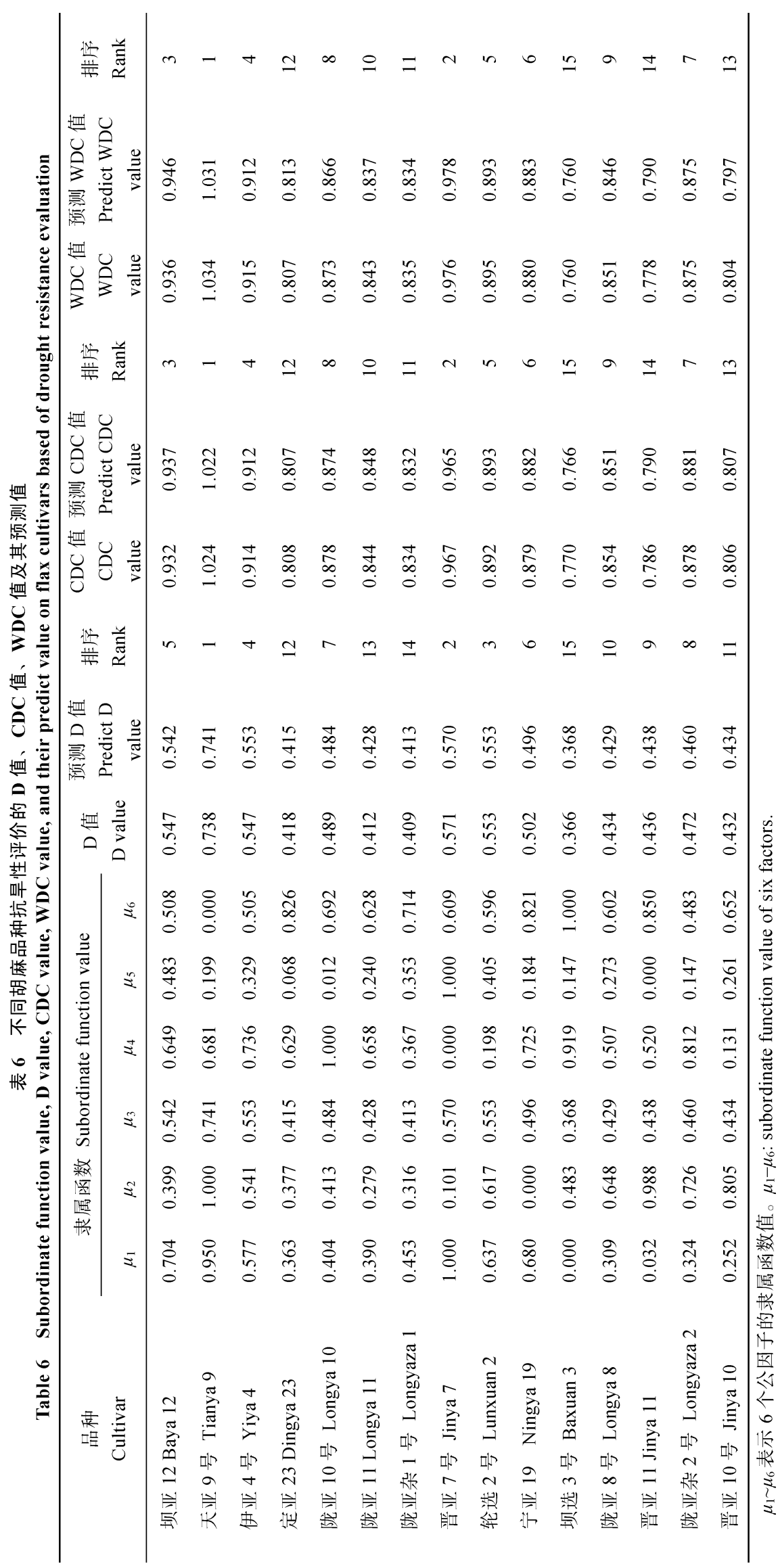


表 7 供试胡麻品种各性状抗旱系数与 D 值、WDC 值的关联度及各性状指标权数

Table 7 Correlation degree between drought resistance coefficients of tested traits and D value, WDC value and traits weight of flax cultivars

\begin{tabular}{|c|c|c|c|c|c|}
\hline $\begin{array}{l}\text { 性状 } \\
\text { Trait }\end{array}$ & $\begin{array}{c}\text { 关联度 } \\
\text { Correlation degree } \gamma^{1)}\end{array}$ & $\begin{array}{l}\text { 位次 } \\
\text { Rank }\end{array}$ & $\begin{array}{c}\text { 性状指标权重 } \\
\text { Weight } \omega_{i(\gamma)} \\
\end{array}$ & $\begin{array}{c}\text { 关联度 } \\
\text { Correlation degree } \gamma^{2)}\end{array}$ & $\begin{array}{l}\text { 位次 } \\
\text { Rank }\end{array}$ \\
\hline 株高 Plant height & 0.676 & 14 & 0.057 & 0.746 & 11 \\
\hline 工艺长度 Processing length & 0.654 & 15 & 0.055 & 0.716 & 14 \\
\hline 有效分枝数 Number of valid branch & 0.740 & 8 & 0.063 & 0.783 & 8 \\
\hline 单株果数 Pods per plant & 0.828 & 1 & 0.070 & 0.859 & 1 \\
\hline 不实果数 Invalid pods & 0.730 & 9 & 0.062 & 0.772 & 9 \\
\hline 单株产量 Grain weight per plant & 0.781 & 6 & 0.066 & 0.820 & 4 \\
\hline 千粒重 1000-grain weight & 0.800 & 2 & 0.068 & 0.841 & 2 \\
\hline 膜透性 Membrane permeability & 0.708 & 12 & 0.060 & 0.760 & 10 \\
\hline 丙二醛 MDA & 0.771 & 7 & 0.065 & 0.796 & 5 \\
\hline 叶绿素 a Chl a & 0.785 & 3 & 0.067 & 0.795 & 6 \\
\hline 叶绿素 b Chl b & 0.710 & 10 & 0.060 & 0.739 & 13 \\
\hline 总叶绿素 TChl & 0.698 & 13 & 0.059 & 0.691 & 15 \\
\hline 过氧化氢酶 CAT & 0.785 & 4 & 0.067 & 0.795 & 7 \\
\hline 超氧化物歧化酶 SOD & 0.710 & 11 & 0.060 & 0.740 & 12 \\
\hline 过氧化物酶 POD & 0.640 & 16 & 0.054 & 0.640 & 16 \\
\hline 籽粒产量 Grain yield & 0.784 & 5 & 0.067 & 0.841 & 3 \\
\hline
\end{tabular}

${ }^{1)} \mathrm{D}$ 值为参考序列; ${ }^{2)} \mathrm{WDC}$ 值为参考序列。 ${ }^{1)} \mathrm{D}$ value is as reference sequences; ${ }^{2)} \mathrm{WDC}$ value is as reference sequences.

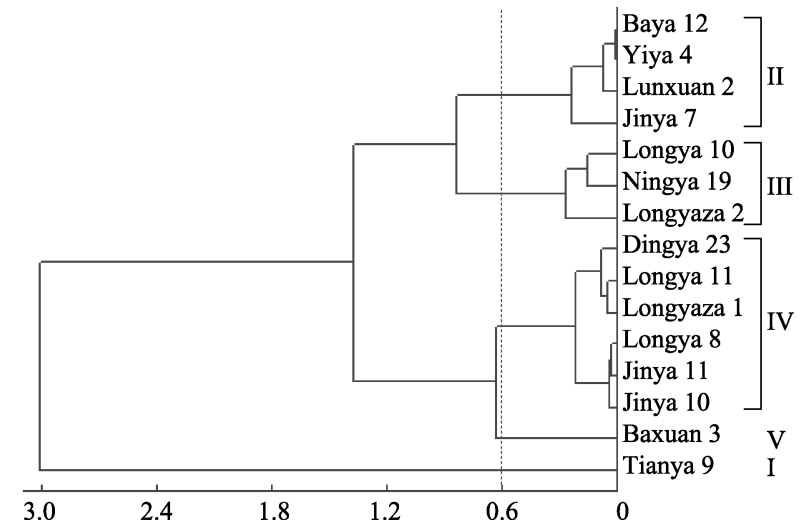

图 3 基于 D 值的供试胡麻品种抗旱性系统聚类图(WPGMA 法)

Fig. 3 Fuzzy clustering dendrogram (WPGMA) of drought resistance of tested flax cultivars based on $D$ values I、II、III、IV、V 表示不同抗旱等级。

I, II, III, IV, and V represent different drought resistance levels.

较为明显，可为其他胡麻品种抗旱级别划分及不同 研究者的相关研究结果之间提供可比较的依据。

2.7 逐步回归分析及抗旱性预测评价

分别利用供试胡麻品种的 D 值、CDC 值、WDC 值与所有性状指标抗旱系数进行逐步回归分析, 得 到回归方程(表9), 进而据回归方程(1)、(2)、(3)对各 指标隶属函数的预测 $\mathrm{D}$ 值与 $\mathrm{D}$ 值、预测 $\mathrm{CDC}$ 值与 CDC 值、预测 WDC 值与 WDC 值做相关性分析, 两 两间均达极显著正相关 $(P<0.01)$; 统计分析显示模
型方程(1)、(2)、(3)的决定系数 $R^{2} \approx 1, F$ 检验均达极 显著水平 $(P<0.01)$, 说明预测值与实际值之间拟合 度好(Durbin-Watson 统计量 $d \approx 2, P<0.01$ ), 回归方 程最优, 其解释能力强, 预测精度高, 用这 3 个方程 进行胡麻品种抗旱性评价预测效果好。

据回归方程(1)可知, 在胡麻品种抗旱性鉴定中, 有选择地测定与 D 值密切相关的指标, 如单株果实、 不实果数、MP、TChl、CAT 等 5 个指标, 可有效鉴 定胡麻品种的抗旱性，从而使鉴定工作简单化。

\section{8 不同抗旱性综合评价方法及度量指标的比较}

基于不同综合评价指标的抗旱性评价结果，基 于 WDC 值和基于 D 值, 供试胡麻品种抗旱性排序 相近, 与位居前 6 位的抗旱品种相同。相关性分析 显示(表 9), 供试品种 D 值、WDC 值、Y 值两两之 间均呈极显著正相关 $(P<0.01)$, 说明以 $\mathrm{D}$ 值为主要 抗旱性综合评价指标, 以 WDC 值作为辅助综合评 价指标, 进行以产量为主要考量目标的胡麻抗旱性 评价是准确的。

另外, 相关性分析还显示, CDC 值与 D 值、Y 值亦达极显著正相关 $(P<0.01)$, 但考虑到其在计 算过程中未考量各性状指标的敏感程度及权重, 仅据此将其作为抗旱性综合评价指标有待进一步 研究。 
表 8 供试胡麻品种不同抗旱性综合评价指标的分级及其评价数据平均值

Table 8 Classification of drought resistance comprehensive evaluation indices of tested flax cultivars and their average of evaluation data

\begin{tabular}{|c|c|c|c|c|c|}
\hline \multirow{2}{*}{$\begin{array}{l}\text { 性状 } \\
\text { Trait }\end{array}$} & \multicolumn{5}{|c|}{$\mu(x)$} \\
\hline & I & II & III & IV & $\mathrm{V}$ \\
\hline 株高 Plant height & 0.839 & 0.603 & 0.403 & 0.530 & 0.634 \\
\hline 工艺长度 Processing length & 1.000 & 0.431 & 0.386 & 0.513 & 0.542 \\
\hline 有效分枝数 Number of valid branch & 1.000 & 0.384 & 0.345 & 0.319 & 0.023 \\
\hline 单株果数 Pods per plant & 1.000 & 0.431 & 0.257 & 0.204 & 0 \\
\hline 不实果数 Invalid pods & 0.080 & 0.538 & 0.175 & 0.182 & 0.292 \\
\hline 单株产量 Grain weight per plant & 0.622 & 0.708 & 0.369 & 0.258 & 0 \\
\hline 千粒重 1000-grain weight & 1.000 & 0.551 & 0.454 & 0.344 & 0 \\
\hline 膜透性 Membrane permeability & 0.476 & 0.304 & 0.429 & 0.134 & 1.000 \\
\hline 丙二醛 MDA & 1.000 & 0.785 & 0.722 & 0.447 & 0 \\
\hline 叶绿素 a Chl a & 0.860 & 0.690 & 0.467 & 0.223 & 0 \\
\hline 叶绿素 b Chl b & 0.222 & 0.411 & 0.730 & 0.439 & 0.949 \\
\hline 总叶绿素 TChl & 0.594 & 0.249 & 0.358 & 0.355 & 0.339 \\
\hline 过氧化氢酶 CAT & 0.860 & 0.690 & 0.467 & 0.223 & 0 \\
\hline 超氧化物歧化酶 SOD & 0.222 & 0.411 & 0.730 & 0.439 & 0.949 \\
\hline 过氧化物酶 POD & 0.623 & 0.727 & 0.146 & 0.615 & 0.340 \\
\hline 籽粒产量 Grain yield & 1.000 & 0.790 & 0.705 & 0.531 & 0 \\
\hline 品种比例 Ratio of tested cultivars (\%) & 6.7 & 26.7 & 20.0 & 40.0 & 6.7 \\
\hline $\mathrm{CDC}$ 值 $\mathrm{CDC}$ value & 1.024 & 0.926 & 0.878 & 0.822 & 0.770 \\
\hline $\mathrm{D}$ 值 $\mathrm{D}$ value & 0.738 & 0.554 & 0.488 & 0.424 & 0.366 \\
\hline WDC 值 WDC value & 1.034 & 0.930 & 0.876 & 0.820 & 0.760 \\
\hline
\end{tabular}

I、II、III、IV、V 表示不同抗旱等级; $\mu(x)$ 表示不同抗旱级别的隶属函数平均值。

I, II, III, IV, and V represent different drought resistance levels. $\mu(x)$ : the average of subordinate function value in different drought resistance level.

表 9 不同胡麻品种抗旱性预测模型及不同综合评价指标间的相关性

Table 9 Predict model of drought resistance and correlation of diffirent comprehensive valuation indices of flax cultivars

\begin{tabular}{|c|c|c|c|c|c|c|c|c|c|c|}
\hline \multirow[b]{2}{*}{$\begin{array}{c}\text { 因变量 } \\
\text { Dependent }\end{array}$} & \multirow[b]{2}{*}{$\begin{array}{l}\text { 多元逐步回归方程 } \\
\text { Stepwise regression }\end{array}$} & \multirow{2}{*}{$\begin{array}{c}\text { 相关 } \\
\text { 系数 } \\
r\end{array}$} & \multirow{2}{*}{$\begin{array}{c}\text { 决定 } \\
\text { 系数 } \\
R^{2}\end{array}$} & \multirow[b]{2}{*}{$F$} & \multirow[b]{2}{*}{$P$} & \multirow[b]{2}{*}{$D^{1)}$} & \multicolumn{4}{|c|}{ 相关系数 $r$} \\
\hline & & & & & & & $\begin{array}{c}\mathrm{D} \text { 值 } \\
\mathrm{D} \text { value }\end{array}$ & $\begin{array}{c}\mathrm{CDC} \text { 值 } \\
\mathrm{CDC} \text { value }\end{array}$ & $\begin{array}{c}\text { WDC 值 } \\
\text { WDC value }\end{array}$ & $\begin{array}{c}\mathrm{Y} \text { 值 } \\
\mathrm{Y} \text { value }\end{array}$ \\
\hline $\begin{array}{l}\text { 综合抗旱性 } \\
\text { 度量值 D }\end{array}$ & $\begin{array}{l}y=-0.163+3.030 x_{4}+0.592 x_{5}+1.731 x_{8}+ \\
2.552 x_{12}+3.486 x_{13}(1)\end{array}$ & 0.998 & $0.995^{* *}$ & $371.914^{* *}$ & 0.0001 & 2.294 & 1 & $0.94^{* *}$ & $0.93^{* *}$ & $0.70^{* *}$ \\
\hline $\begin{array}{l}\text { 综合抗旱 } \\
\text { 系数 CDC }\end{array}$ & $\begin{array}{l}y=0.337+0.664 x_{3}+1.718 x_{4}+1.462 x_{5}+ \\
1.424 x_{12}+1.545 x_{13}+1.335 x_{15}+1.926 x_{16}\end{array}$ & 0.999 & $0.998^{* *}$ & $519.453^{* *}$ & 0.0001 & 2.038 & - & 1 & $1.00^{* *}$ & $0.82^{* *}$ \\
\hline $\begin{array}{l}\text { 加权抗旱 } \\
\text { 系数 WDC }\end{array}$ & $\begin{array}{l}y=0.349+2.145 x_{4}+1.491 x_{5}+1.483 x_{12}+ \\
1.500 x_{13}+1.153 x_{15}+2.139 x_{16}(3)\end{array}$ & 0.997 & $0.994^{* *}$ & $211.888^{* *}$ & 0.0001 & 2.165 & - & - & 1 & $0.83^{* *}$ \\
\hline
\end{tabular}

$x_{3}$ : 有效分枝数; $x_{4}$ ：单株果数; $x_{5}$ : 不实果数; $x_{8}$ ：膜透性; $x_{12}$ ：总叶绿素; $x_{13}$ ：过氧化氢酶; $x_{15}$ ：过氧化物酶; $x_{16}$ ：产量。 ${ }^{1)} \mathrm{D}$ : $\mathrm{W}$ 统计 量 $(d),{ }^{* *}$ 表示 $P=0.01$ 水平相关性极显著。

$x_{3}$ : number of valid branch (NVB); $x_{4}$ : number of valid branch (NVB); $x_{5}$ : invalid pods (IP); $x_{8}$ : membrane permeability (MP); $x_{12}$ :TChl; $x_{13}$ : CAT; $x_{15}$ : POD; $x_{16}$ : grain yield $(\mathrm{Y}) .{ }^{1)} D$ : W statistics $(d),{ }^{* *}$ Significant at 0.01 probability level.

\section{3 讨论}

\section{1 关于抗旱评价指标的选择问题} 性状指标的合理选择是作物抗旱性鉴定的关键,
对此目前国内外进行了大量研究 ${ }^{[1,2,7-19]}$, 并从不同 角度提出了抗旱性鉴定的相关性状。Zhang等 ${ }^{[24}$ 和孟 庆立等 ${ }^{[16]}$ 对谷子成株期抗旱性研究认为, 产量性状 对干旱胁迫最敏感。Chernyad'ev等 ${ }^{[25]}$ 和王士强等 ${ }^{[1]}$ 
认为小麦生理生化性状的影响大于农艺性状; Tambussi等 ${ }^{[26]}$ 和李贵全等 ${ }^{[12]}$ 研究表明大豆农艺性状的 综合指标与品种的抗旱性显著相关。然而, 不同鉴 定指标对干旱胁迫的敏感程度、不同指标间有何关 系, 对抗旱性的贡献等问题, 目前尚无定论, 且多 数研究未将农艺性状和生理指标结合起来考虑。

关联度反映的是构成该系统的各性状组成的比 较数列和参考数列间的密切程度 ${ }^{[1,23]}$ 。本研究选取与 胡麻抗旱性相关的 16 个关键农艺性状及生理生化性 状为指标, 其结合起来, 从宏观和微观层面对抗旱 性的内在机制认识和分析, 结果显示, 与抗旱性度 量值(D值)的关联程度较高的 6 个性状依次为单株果 实、千粒重、CAT、Chl a、产量抗旱系数、单株产 量, 这和各性状抗旱系数与加权抗旱系数(WDC值) 的密切程度相吻合, 说明基于D值和WDC值的性状 关联度评价是适宜且准确的, 进而提示我们, 除以 产量等核心农艺性状作为胡麻抗旱性節选指标外, 还应重视CAT、MDA、Chl a等生化指标的分析, 以提 高判断的准确性, 这与前人的研究结果是一致的 ${ }^{[9,15]}$ 。 而与小麦等作物明显不同的是, 胡麻株高、工艺长 度等性状与其抗旱性关联较弱, 不宜作为品种抗旱 性选择的核心指标。

从抗旱性状因子分析的结果可以看出, 单株果 实、单株产量、千粒重、 $\mathrm{Chl} \mathrm{a} 、 \mathrm{CAT}$ 占据了首要位 置, 表明在干旱条件下产量相关性状是胡麻不同基 因型间抗旱性的重要体现, 这与祁旭升等 ${ }^{[2]}$ 的研究 结果相近; 而干旱条件下的地上部分光合作用和抗 氧化能力与其抗旱性密切相关。可见, 除丰产性是 胡麻抗旱性重要外在表现外, 良好的逆境生理调控 能力、繁茂的生物积累量和流畅的根系物质转储能 力 $^{[27]}$ 是影响胡麻抗旱性的重要因素, 这与孟庆立等 ${ }^{[16]}$ 的研究结论相近。

\section{2 作物抗旱性的分析方法}

近年国内外学者针对不同作物和不同育种需求 从不同角度研究和提出了更加全面的抗旱评价鉴定

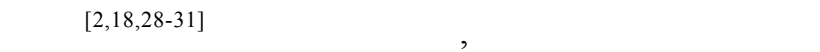
的抗旱性综合评价比较可靠 ${ }^{[2]}$ 。本研究认为各性状 指标权重及最终核心综合评价指标的确定往往是抗 旱性综合评价的关键。

本研究采用 $\mathrm{D}$ 值、综合抗旱系数( $\mathrm{CDC}$ 值)、WDC 值、 $\mathrm{Y}$ 值等综合评价其抗旱性, 确定 D 值及 WDC 值为综合评价指标, 进行较确切的聚类分析和抗旱 型划分，并结合灰色关联分析、逐步回归分析篮选
关键性状指标，建立了拟合度较好的回归方程。结 果显示, 以 $\mathrm{D}$ 值为主要综合评价指标、以 WDC 作 为辅助综合评价指标, 评价以产量为主要考量目标 的胡麻抗旱性是适宜且准确的。虽然 CDC 值与 D 值亦达极显著正相关，但在其计算过程中未考量各 性状指标的敏感程度、重要性及权重，是否能将其 作为抗旱性综合评价指标有待进一步研究确认。另 外, 本研究依据 $\mathrm{D}$ 值进行抗旱级别的划分, 并提供 相应抗旱级别的 D 值、CDC 值和 WDC 值, 可为其 他胡麻品种抗旱级别划分及不同研究者的相关研究 结果之间提供可比较的依据。

本研究结果也说明产量相关性状仍是决定胡麻 抗旱性的根本因素，这与孟庆立等 ${ }^{[16]}$ 对谷子成株期 抗旱性研究结论相同。而利用本研究所建立最优回 归方程可有效预测所测品种抗旱性的强弱，提高抗 旱育种效率。故笔者认为, 基于 $\mathrm{D}$ 值的抗旱性鉴定和 抗旱型划分能很好地反映各品种抗旱性、抗旱特点 及选育和应用区域，进而提示我们采用隶属函数法 及综合/加权抗旱系数法, 并结合灰色关联分析法评 价胡麻品种抗旱性, 结果客观、可靠。

\section{4 结论}

采用抗旱性综合评价方法, 确定抗旱性度量值 (D值)及加权抗旱系数 (WDC 值) 为综合评价指标, 进 行聚类分析和抗旱型划分，并结合灰色关联分析、 逐步回归分析篮选出关键性状指标，建立了回归方 程, 能有效反映各参试品种抗旱性、抗旱特点, 为参 试品种在育种及适应区域的合理利用及其他品种 (系)的抗旱性鉴定提供有价值的参考。

\section{References}

[1] 王士强, 胡银岗, 余奎军, 周琳璘, 孟凡否. 小麦抗旱相关农 艺性状和生理生化性状的灰色关联度分析. 中国农业科学, 2007, 40: 2452-2459

Wang S Q, Hu Y G, She K J, Zhou L L, Meng F L. Gray relational grade analysis of agronomical and physi-biochemical traits related to drought tolerance in wheat. Sci Agric Sin, 2007, 40: 2452-2459 (in Chinese with English abstract)

[2] 祁旭升, 王兴荣, 许军, 张建平, 米君. 胡麻种质资源成株期 抗旱性评价. 中国农业科学, 2010, 43: 3076-3087

Qi X S, Wang X R, Xu J, Zhang J P, Mi J. Drought-resistance evaluation of flax germplasm at adult plant stage. Sci Agric Sin, 2010, 43: 3076-3087 (in Chinese with English abstract)

[3] 赵利, 党占海, 张建平, 关天霞, 田彩萍. 不同类型胡麻品种 资源品质特性及其相关性研究. 干旱地区农业研究，2008， 26(5): 6-9

Zhao L, Dang Z H, Zhang J P, Guan T X, Tian C P. Study on 
quality characters and correlation of different types of flax germplasm. Agric Res Arid Areas, 2008, 26(5): 6-9 (in Chinese with English abstract)

[4] 张木清, 陈如凯. 作物抗旱分子生理与遗传改良. 北京: 科学 出版社, 2005. pp 22-23

Zhang M Q, Chen R K. Molecular Physiological and Genetic Improvement of Crop Drought Tolerance. Beijing: Science Press, 2005. pp 22-23 (in Chinese)

[5] 张正斌. 作物抗旱节水的生理遗传育种基础. 北京: 科学出版 社, 2003. pp 67-209

Zhang Z B. Fundamentals of Physiological and Genetic Breeding Basis in Crop Drought Resistance and Water Saving. Beijing: Science Press, 2003. pp 67-209 (in Chinese)

[6] Kamoshita A, Babu R C, Boopathi N M, Fukai S. Phenotypic and genotypic analysis of drought-resistance traits for development of rice cultivars adapted to rainfed environments. Field Crops Res, 2008, 109: 1-23

[7] Upadhyaya H D. Variability for drought resistance related traits in the mini core collection of peanut. Crop Sci, 2005, 45: $1432-1440$

[8] Hura T, Hura K, Grzesiak S. Physiological and biochemical parameters for identification of QTLs controlling the winter triticale drought tolerance at the seedling stage. Plant Physiol Biochem, 2009, 47: 210-214

[9] 王贺正, 马均, 李旭毅, 李艳, 张荣萍, 汪仁全. 水稻开花期 一些生理生化特性与品种抗旱性的关系. 中国农业科学, 2007, 40: 399-404

Wang H Z, Ma J, Li X Y, Li Y, Zhang R P, Wang R Q. Relationship between some physiological and biochemical characteristics and drought tolerance at rice flowering stage. Sci Agric Sin, 2007, 40: 399-404 (in Chinese with English abstract)

[10] 武斌, 李新海, 肖木辑, 谢传晓, 郝转芳, 李明顺, 张世煌. 53 份玉米自交系的苗期耐旱性分析. 中国农业科学, 2007, 40: 665-676

Wu B, Li X H, Xiao M J, Xie C X, Hao Z F, Li M S, Zhang S H. Genetic variation in fifty three maize inbred lines in relation to drought tolerance at seedling stage. Sci Agric Sin, 2007, 40: 665-676 (in Chinese with English abstract)

[11] 白志英, 李存东, 孙红春, 赵金锋. 小麦代换系抗旱生理指标 的主成分分析及综合评价. 中国农业科学, 2008, 41: 4264-4272

Bai Z Y, Li C D, Sun H C, Zhao J F. Principal component analysis and comprehensive evaluation on physiological indices of drought resistance in wheat substitution. Sci Agric Sin, 2008, 41: 4264-4272 (in Chinese with English abstract)

[12] 李贵全, 张海燕, 季兰, 赵二开, 刘建兵, 李玲, 张家蓉. 不同 大豆品种抗旱性综合评价。应用生态学报, 2006, 17: 2408-2412

Li G Q, Zhang H Y, Ji L, Zhao E K, Liu J B, Li L, Zhang J R. Comprehensive evaluation on drought-resistance of different soybean varieties. Chin J Appl Ecol, 2006, 17: 2408-2412 (in Chinese with English abstract)

[13] 孔照胜, 武云帅, 岳爱琴, 李贵全, 彭永康. 不同大豆品种抗 旱性生理指标综合分析. 华北农学报, 2001, 16(3): 40-45 Kong Z S, Wu Y S, Yue A Q, Li G Q, Peng Y K. Comprehensive analysis of physiological indexes for drought resistance in differ- ent soybean varieties. Acta Agric Boreali-Sin, 2001, 16(3): 40-45 (in Chinese with English abstract)

[14] 朱宗河, 郑文寅, 张学昆. 甘蓝型油菜耐旱相关性状的主成分 分析及综合评价. 中国农业科学, 2011, 44: 1775-1787

Zhu Z H, Zheng W Y, Zhang X K. Principal component analysis and comprehensive evaluation on morphological and agronomic traits of drought tolerance in rapeseed (Brassica napus L.). Sci Agric Sin, 2011, 44: 1775-1787 (in Chinese with English abstract)

[15] 谢小玉, 张霞, 张兵. 油菜苗期抗旱性评价及抗旱相关指标变 化分析. 中国农业科学, 2013, 46: 476-485

Xie X Y, Zhang X, Zhang B. Evaluation of drought resistance and analysis of variation of relevant parameters at seedling stage of rapeseed (Brassica napus L.). Sci Agric Sin, 2013, 46: 476-485 (in Chinese with English abstract)

[16] 孟庆立, 关周博, 冯佰利, 柴岩, 胡银岗. 谷子抗旱相关性状 的主成分与模糊聚类分析. 中国农业科学, 2009, 42: 2667-2675

Meng Q L, Guan Z B, Feng B L, Chai Y, Hu Y G. Principal component analysis and fuzzy clustering on drought tolerance related traits of foxtail millet (Setaria italica). Sci Agric Sin, 2009, 42: 2667-2675 (in Chinese with English abstract)

[17] 徐芯, 王启柏, 张春庆, 吴承来. 玉米自交系抗旱性评价指标 体系的建立. 中国农业科学, 2009, 42: 72-84

Xu R, Wang Q B, Zhang C Q, Wu C L. Drought resistance evaluation system of maize inbred. Sci Agric Sin, 2009, 42: 72-84 (in Chinese with English abstract)

[18] 罗俊杰, 石有太, 陈玉梁, 王红梅, 刘新星. 甘肃不同色彩陆 地棉抗旱指标篮选及评价研究. 核农学报, 2012, 26: 952-959

Luo J J, Shi Y T, Chen Y L, Wang H M, Liu X X. Screening and wvaluation of drought tolerant indices of colored upland cotton (Gossypium hirsutum L.) in Gansu. Acta Agric Nucl Sin, 2012, 26: 952-959 (in Chinese with English abstract)

[19] 石仓吉. 亚麻品种抗旱性评价研究. 干旱地区农业研究, 2008, 26(5): $1-5$

Shi C J. Research on assessment of flax drought resistance. Agric Res Arid Areas, 2008, 26(5): 1-5 (in Chinese with English abstract)

[20] 刍琦. 植物生理学实验指导. 北京: 中国农业出版社, 2000. pp 41-184

Zou Q. Guidebook of Plant Physiology Experiments. Beijing: China Agriculture Press, 2000. pp 41-184 (in Chinese)

[21] 王玉富, 粟建光. 亚麻种质资源描述规范和数据标准. 北京: 中国农业出版社, 2006. pp 1-99

Wang Y F, Su J G. Descriptors and Data Standard for Flax (Linum usitatissimum L.). Beijing: China Agriculture Press, 2006. pp 1-99 (in Chinese)

[22] 兰巨生. 农作物综合抗旱性评价方法的研究. 西北农业学报, 1998, 7(3): 85-87

Lan J S. Comparison of evaluating methods for agronomic drought resistance in crops. Acta Agric Boreali-Occident Sin, 1998, 7(3): 85-87 (in Chinese with English abstract)

[23] 尹利, 逯晓萍, 傅晓峰, 李美娜, 郭建. 高丹草杂交种灰色关 联分析与评判. 中国草地学报, 2006, 28: 21-25

Yin L, Lu X P, Fu X F, Li M N, Guo J. The grey relation analysis and evaluation of hybrid pacesetter. Chin J Grassl, 2006, 28: 
21-25 (in Chinese with English abstract)

[24] 张霞, 谢小玉. PEG 胁迫下甘蓝型油菜种子萌发期抗旱鉴定指 标的研究. 西北农业学报, 2012, 21(2): 72-77

Zhang X, Xie X Y. Studies on identification indexes of drought resistance by PEG during seed germination of rapeseed (Brassica napus L.). Acta Agric Boreali-Occident Sin, 2012, 21(2): 72-77 (in Chinese with English abstract)

[25] Chernyad'ev I I, Monakhova O F. Effects of cytokinin preparations on the pools of pigments and proteins of wheat cultivars differing in their tolerance to water stress. Appl Biochem Micro, 2003, 39: 524-531

[26] Tambussi E A, Nogués S, Araus J L. Ear of durum wheat under water stress: water relations and photosynthetic metabolism. Planta, 2005, 221: 446-458

[27] Manschadi A M, Hammer G L, Christopher J T, de Voil P. Genotypic variation in seedling root architectural traits and implications for drought adaptation in wheat (Triticum aestivum L.). Plant Soil, 2008, 303: 115-129

[28] Condon A G, Richards R A, Rebetzke G J, Farquhar G D. Breed- ing for high water use efficiency. $J$ Exp Bot, 2004, 55: 2447-2460

[29] Subrahmanyam D, Subash N, Haris A, Sikka A K. Influence of water stress on leaf photosynthetic characteristics in wheat cultivars differing in their susceptibility to drought. Photosynthetica, 2006, 44: $125-129$

[30] 陈玉梁, 石有太, 罗俊杰, 王蒂, 厚毅清, 李忠旺, 张秉贤. 甘 肃彩色棉花抗旱性农艺性状指标的篮选鉴定. 作物学报, 2012, 38: $1680-1687$

Chen Y L, Shi Y T, Luo J J, Wang D, Hou Y Q, Li Z W, Zhang B $\mathrm{X}$. Screening of drought tolerant agronomic trait indices of colored cotton varieties (lines) in Gansu Province. Acta Agron Sin, 2012, 38: 1680-1687 (in Chinese with English abstract)

[31] 陈玉梁, 石有太, 罗俊杰, 李忠旺, 厚毅清, 王蒂. 干旱胁迫 对彩色棉花农艺、品质性状及水分利用效率的影响. 作物学报, 2013, 39: 2074-2082

Chen Y L, Shi Y T, Luo J J, Li Z W, Hou Y Q, Wang D. Effect of drought stress on agronomic traits, quality, and WUE in different colored upland cotton varieties (lines). Acta Agron Sin, 2013, 39: 2074-2082 (in Chinese with English abstract) 